\title{
Styloid Process of the Temporal Bone: Morphometric Analysis and Clinical Implications
}

\author{
Antonio Luis Neto Custodio, ${ }^{1}$ Micena Roberta Miranda Alves e Silva, \\ Mauro Henrique Abreu, ${ }^{2}$ Lucas Rodarte Abreu Araújo, ${ }^{3}$ \\ and Leandro Junqueira de Oliveira ${ }^{3}$ \\ ${ }^{1}$ Department of Morphology, Institute Of Biological Sciences, University Federal of Minas Gerais, Belo Horizonte, MG, Brazil \\ ${ }^{2}$ Department of Community and Preventive Dentistry, University Federal of Minas Gerais, Belo Horizonte, MG, Brazil \\ ${ }^{3}$ Postgraduate Program of Pontifical Catholic University of Minas Gerais, Belo Horizonte, MG, Brazil
}

Correspondence should be addressed to Antonio Luis Neto Custodio; drantonio@ufmg.br

Received 11 July 2016; Revised 24 August 2016; Accepted 28 August 2016

Academic Editor: Gasparini Giulio

Copyright (C) 2016 Antonio Luis Neto Custodio et al. This is an open access article distributed under the Creative Commons Attribution License, which permits unrestricted use, distribution, and reproduction in any medium, provided the original work is properly cited.

\begin{abstract}
Objective. To evaluate measures of the styloid process (SP) in Brazilian dry skulls. Methods. This study involves measurements of two points (lateral end posterior views) of 15 dry skulls held by the Morphology Department, Institute of Biological Sciences of Federal University of Minas Gerais. Results. There was a large variability for the length of left and right sides (in lateral and posterior views) of the styloid process. From the lateral view of the left and right styloid, the length of the SP ranged, respectively, from $10.22 \mathrm{~mm}$ to $69.73 \mathrm{~mm}$ and from $8.30 \mathrm{~mm}$ to $63.77 \mathrm{~mm}$. From a posterior view of the left and right sides of the skulls, the values range, respectively, from $15.57 \mathrm{~mm}$ to $69.51 \mathrm{~mm}$ and from $15.64 \mathrm{~mm}$ to $69.44 \mathrm{~mm}$. Conclusion. We believe that this study provides additional information about the frequency of elongated SP among the Brazilian population.
\end{abstract}

\section{Introduction}

The styloid process (SP) consists of two narrow and elongated bony projections of the temporal bone. They are located anteriorly to the stylomastoid foramen on the right and left sides of base of the skull [1]. This bone process presents three muscles (stylopharyngeus, stylohyoid, and styloglossus) and two ligaments (stylohyoid and stylomandibular) attached to it [2] (Figure 1).

The length of SP ranges from $15.2 \mathrm{~mm}$ to $47.7 \mathrm{~mm}$ [3], although several authors have reported that the normal length of this structure is between $20 \mathrm{~mm}$ and $30 \mathrm{~mm}$ [48], with length longer than $30 \mathrm{~mm}$ considered elongated. This elongation of the styloid process or calcification of ligaments, which is the cause of the stylohyoid syndrome or Eagle syndrome, was first reported by the otorhinolaryngologist Eagle (1937) [9]. Patients diagnosed with Eagle syndrome may present dysphagia; pain usually focuses on the angle of the mandible and worsens during the rotation of neck or protrusion of the tongue $[9,10]$. However, the condition is usually asymptomatic and observed incidentally on a radiographic exam $[3,11]$. The relationship between SP and hyoid bone forms the anatomical basis for the glossopharyngeal neurological symptoms associated with elongated styloid process syndrome [12]. Commonly this affects adults bilaterally but may affect only one side of the head [13].

The location of this process is extremely important because it relates to important neurovascular structures. SP is located thereafter in the wall of pharynx and between internal and external carotid arteries and the internal jugular vein. Furthermore, the glossopharyngeal, facial, accessory, hypoglossal, vagus, and other nerves present trajectories that are next to SP. The elongation of this process can cause irritation in various structures next to it [14].

Diagnosis can be made clinically if the elongated styloid process is palpable in the ipsilateral tonsillar fossa. However, 


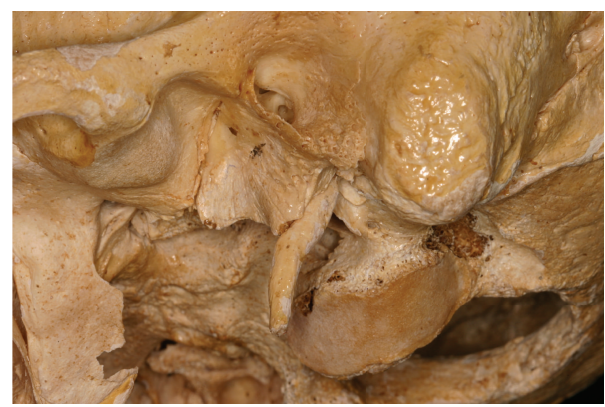

FIGURE 1: Styloid process.

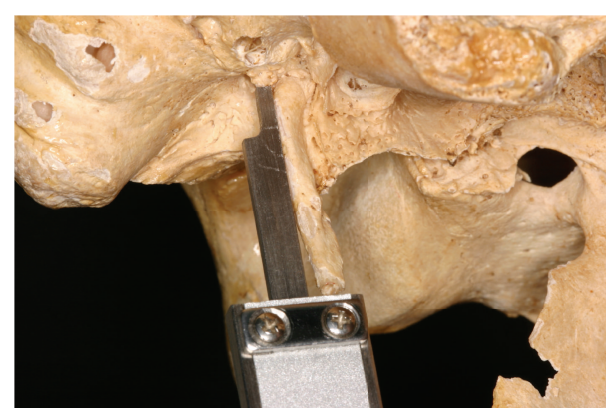

FIgURE 2: Posterior view.

the panoramic radiograph requested for other reasons often points to the diagnosis of the syndrome, considering that most patients are asymptomatic [15]. An accurate clinical and radiological evaluation and an experienced professional are important to perform the correct diagnosis. The treatment may be performed by an extraoral or intraoral surgical approach [16].

The aim of the present study was to evaluate measures of the styloid process on Brazilian dry skulls.

\section{Methods}

A total of 109 dry skulls held by the Morphology Department, Institute of Biological Sciences, Federal University of Minas Gerais, were analyzed. Included in the study were specimens that exhibited the two styloid processes without damage and/or fracture signs. An exclusion of 94 dry skulls was necessary, resulting in a sample of 15 skulls.

Two points were determined to standardize measurements, which were obtained using a digital caliper by three observers. The measures were as follows.

(1) Posterior Measure. This was obtained by measuring the distance from the tip of the styloid process to the flat surface on the side of stylomastoid foramen (Figure 2).

(2) Side Measure. This was obtained by measuring the distance from the tip of the styloid process to its base, on the side of it, where it joins the surface of the anterior wall of the ear canal (Figure 3).

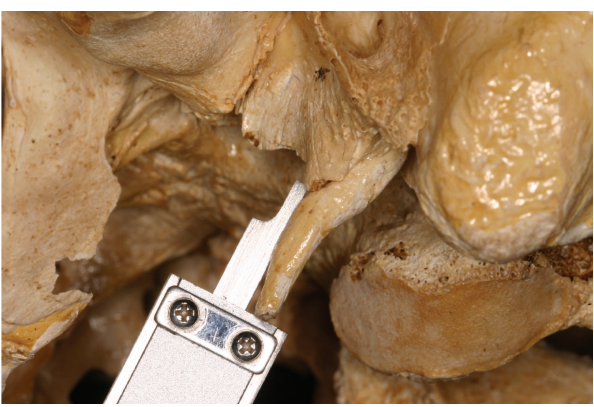

Figure 3: Lateral view.

2.1. Statistical Analysis. The measures of three observers were synthetized in only one mean measure. Descriptive statistics involved the calculation of central tendency and dispersion measures for each side of the styloid process and for each anatomic position (posterior or lateral). We checked for the normal distribution of each variable, using Shapiro-Wilk tests $(p<0.05)$. We compared the measures for the both sides of the styloid process in each anatomic position, using Wilcoxon tests $(p<0.05)$.

\section{Results}

There was a large variability in the length of left and right sides of the styloid process (in lateral and posterior views). There was no normal distribution for these measures $(p<0.001)$. The central tendency measures of each side in each view are presented on Table 1. There was no difference in the length of styloid process when the sides were compared for each view $(p>0.05)$. The measures obtained by the observers are presented in Table 2.

\section{Discussion}

During embryological development, the SP came from Reichert's cartilage of the second pharyngeal arch [17]. Its length ranges from $15.2 \mathrm{~mm}$ to $47.7 \mathrm{~mm}$ [3], but other studies have found different dimensions: Jung et al. (2004) [18] suggested that the length of this bone process was longer when it presents more than $45 \mathrm{~mm}$. These variations can occur due to the technique used to measure this length.

There are a variety of ways to determine the dimensions of SP and diagnose Eagle syndrome: panoramic radiographs, $\mathrm{X}$-ray lateral views of the neck, orthopantomograms, and computed tomography. In addition, many studies are based on measurements of dry skulls or cadavers. In some cases the elongated SP can be clinically detected by palpating the tonsillar fossa [19]. Eagle syndrome, or elongated styloid process syndrome, is associated with such symptoms as chronic facial and neck pain, dysphagia, tinnitus, referred pain in the ear, glossopharyngeal neuralgia, orbital pain, and radiating pain in the maxillary regions, which worsen when the head rotates or the tonsillar fossa region is palpated [20].

The cause of elongation of SP is poorly understood, but the most common theories propose congenital elongation of the styloid process, calcification of the stylohyoid ligament by 
TABLE 1: Measurements of the styloid processes, considering the right and left sides of the skulls.

\begin{tabular}{lcccc}
\hline & $\begin{array}{c}\text { Left styloid process } \\
\text { length (lateral view) }\end{array}$ & $\begin{array}{c}\text { Right styloid process } \\
\text { length (lateral view) }\end{array}$ & $\begin{array}{c}\text { Left styloid process } \\
\text { length (posterior } \\
\text { view) }\end{array}$ & $\begin{array}{c}\text { Right styloid process } \\
\text { length (posterior } \\
\text { view) }\end{array}$ \\
\hline Mean (SD) & $19.25(14.54)$ & $18.90(13.14)$ & $24.98(12.94)$ & $26.04(12.65)$ \\
Minimum & 10.22 & 8.30 & 15.57 & 24.01 \\
Median & 14.87 & 14.37 & 23.11 & 69.44 \\
Maximum & 69.73 & 63.77 & 69.51 & 0.088 \\
\hline p value* & & & &
\end{tabular}

TABLE 2: Measurements of the styloid processes by observers.

\begin{tabular}{|c|c|c|c|c|c|c|}
\hline \multirow{3}{*}{ Skull } & \multicolumn{6}{|c|}{ Measurements in milimeters } \\
\hline & \multicolumn{2}{|c|}{ Examiner 1} & \multicolumn{2}{|c|}{ Examiner 2} & \multicolumn{2}{|c|}{ Examiner 3} \\
\hline & Lateral & Posterior & Lateral & Posterior & Lateral & Posterior \\
\hline E1 left & 69,80 & 69,39 & 69,47 & 69,54 & 69,93 & 69,60 \\
\hline E1 right & 63,65 & 69,69 & 63,88 & 69,21 & 63,78 & 69,41 \\
\hline E2 left & 14,41 & 23,05 & 14,58 & 23,18 & 14,10 & 23,25 \\
\hline E2 right & 14,16 & 25,46 & 14,63 & 25,90 & 14,31 & 25,50 \\
\hline E3 left & 14,91 & 23,08 & 14,80 & 23,13 & 14,89 & 23,11 \\
\hline E3 right & 13,25 & 24,25 & 13,17 & 24,24 & 13,82 & 24,37 \\
\hline E4 left & 10,45 & 15,71 & 10,14 & 15,55 & 10,07 & 15,45 \\
\hline E4 right & 8,21 & 15,66 & 8,55 & 15,40 & 8,14 & 15,85 \\
\hline E5 left & 20,50 & 23,87 & 20,32 & 23,91 & 20,56 & 23,98 \\
\hline E5 right & 17,60 & 26,68 & 17,57 & 26,93 & 17,64 & 26,87 \\
\hline E6 left & 14,30 & 20,40 & 14,35 & 20,33 & 14,46 & 20,51 \\
\hline E6 right & 13,62 & 19,88 & 13,50 & 20,16 & 13,62 & 19,89 \\
\hline E7 left & 11,37 & 17,65 & 11,47 & 17,91 & 11,32 & 17,82 \\
\hline E7 right & 13,63 & 18,53 & 13,73 & 18,06 & 13,92 & 18,04 \\
\hline E8 left & 23,15 & 25,53 & 22,92 & 25,46 & 22,98 & 25,51 \\
\hline E8 right & 24,48 & 26,54 & 25,02 & 26,52 & 24,49 & 26,56 \\
\hline E9 left & 20,46 & 29,40 & 20,71 & 29,31 & 20,80 & 29,12 \\
\hline E9 right & 21,53 & 30,75 & 21,80 & 31,00 & 21,46 & 30,80 \\
\hline E10 left & 16,08 & 22,09 & 16,28 & 22,30 & 16,31 & 22,18 \\
\hline E10 right & 16,98 & 21,77 & 16,71 & 21,25 & 16,78 & 21,40 \\
\hline E11 left & 14,44 & 20,46 & 14,71 & 20,38 & 14,30 & 20,55 \\
\hline E11 right & 13,76 & 19,80 & 13,80 & 20,05 & 13,95 & 19,98 \\
\hline E12 left & 10,81 & 16,08 & 10,69 & 16,40 & 10,62 & 16,26 \\
\hline E12 right & 11,55 & 24,14 & 11,27 & 23,96 & 11,23 & 23,93 \\
\hline E13 left & 19,36 & 25,31 & 19,08 & 25,15 & 19,44 & 25,19 \\
\hline E13 right & 19,91 & 25,60 & 19,98 & 25,70 & 19,97 & 26,07 \\
\hline E14 left & 18,78 & 25,75 & 18,70 & 25,86 & 18,51 & 25,50 \\
\hline E14 right & 19,14 & 23,35 & 19,02 & 23,47 & 19,26 & 23,42 \\
\hline E15 left & 10,33 & 16,63 & 10,29 & 16,73 & 10,30 & 16,70 \\
\hline E15 right & 11,76 & 18,82 & 11,21 & 18,43 & 11,13 & 18,54 \\
\hline
\end{tabular}

an unknown process, and growth of osseous tissue where the stylohyoid ligament inserts [11, 17].

Understanding the frequency of elongated SP in Brazil can help clinicians diagnose Eagle syndrome and treat it. In the present study, the length of the SP ranged from $10.22 \mathrm{~mm}$ to $69.73 \mathrm{~mm}$ and from $8.30 \mathrm{~mm}$ to $63.77 \mathrm{~mm}$, based on the lateral view of the left and right styloid, respectively. From the posterior view, the values for the left and right sides of the skulls, respectively, ranged from $15.57 \mathrm{~mm}$ to $69.51 \mathrm{~mm}$ and from $15.64 \mathrm{~mm}$ to $69.44 \mathrm{~mm}$. According to the three observers in this study, from the right to the left view, the mean length of the styloid process was $19.25 \mathrm{~mm}$ and 


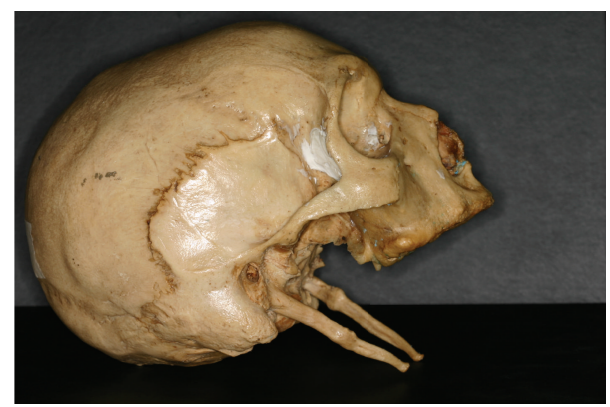

FIGURE 4: Elongated SP (skull E1 of the study).

$18.90 \mathrm{~mm}$ in the lateral view and $24.98 \mathrm{~mm}$ and $26.04 \mathrm{~mm}$, in the posterior view. The normal length of SP varies in the literature from $15.2 \mathrm{~mm}$ to $47.7 \mathrm{~mm}$, according to Moffat et al. (1977) [1]; measures less than $30 \mathrm{~mm}$, according to Kaufman et al. (1970) [21]; and measures from $20 \mathrm{~mm}$ to $30 \mathrm{~mm}$, according to Lindeman (1985) [22]. Considering the normal length of SP as defined by Eagle (i.e., $25 \mathrm{~mm}$ to $30 \mathrm{~mm}$ ) (1937) [9], the presence of one elongated SP was observed in this research among 15 dry skulls with a prevalence rate of $6.6 \%$ of the total analyzed (Figure 4). The prevalence of elongated styloid process in the earlier studies was $1 \%$ [23], 4\% [24], and $8.2 \%$ [25]. The $4 \%$ prevalence rate in the present study is similar to the rate observed by Eagle. Other Indian studies by Rathva et al. (2013) [26] reported the prevalence of elongated styloid process as up to $2 \%$.

Other authors report that the Eagle syndrome is not only a long stylohyoid process; other factors are necessary for a diagnosis [27].

The pathophysiological mechanisms for the pain associated with Eagle syndrome include

(1) compression of the neural elements (i.e., glossopharyngeal nerve, lower branch of the trigeminal nerve, and/or the chorda tympani);

(2) fracture of the ossified stylohyoid ligament, followed by inflammatory reaction;

(3) impingement on the carotid vessels by the SP, producing irritation of the sympathetic nerves in the arterial sheath;

(4) degenerative and inflammatory changes in the tendinous portion of the stylohyoid insertion;

(5) irritation of the pharyngeal mucosa by direct compression;

(6) stretching and fibrosis involving the fifth, seventh, ninth, and tenth cranial nerves in the posttonsillectomy period [28].

\section{Conclusion}

The study and knowledge of the anatomical variations of the SP in a population may help clinicians from various specialties to diagnose Eagle syndrome. Knowledge of this disorder can prevent the worsening of the painful symptoms related to the elongated SP. We believe that this study provides additional information about the frequency of elongated styloid process in the Brazilian population. Nevertheless, the actual research would be more accurate with a larger number of samples. Another limitation of the present study is the lack of gender-related variation which was not taken into consideration.

\section{Ethical Approval}

Ethical approval was obtained from the Research Ethics Committee of Federal University of Minas Gerais, which granted approval no. 48473415.0.0000.5149.

\section{Competing Interests}

All the authors declare that there were no known competing interests associated with this publication and there has been no financial support for this work that could have influenced its outcome.

\section{Authors' Contributions}

The authors contributed equally to this work.

\section{References}

[1] D. A. Moffat, R. T. Ramsden, and H. J. Shaw, "The styloid process syndrome: aetiological factors and surgical management," Journal of Laryngology and Otology, vol. 91, no. 4, pp. 279-294, 1977.

[2] J. J. Keur, J. P. S. Campbell, J. F. McCarthy, and W. J. Ralph, "The clinical significance of the elongated styloid process," Oral Surgery, Oral Medicine, Oral Pathology, vol. 61, no. 4, pp. 399404, 1986.

[3] R. D. Murtagh, J. T. Caracciolo, and G. Fernandez, "CT findings associated with Eagle syndrome," American Journal of Neuroradiology, vol. 22, no. 7, pp. 1401-1402, 2001.

[4] C. Gokce, Y. Sisman, E. E. Tarim, F. Akgunlu, and A. Ozturk, "Prevalence of styloid process elongation on panoramic radiography in the Turkey population from Cappodocia region," European Journal of Dentistry, vol. 2, pp. 18-22, 2008.

[5] Y. Sisman, C. Gokce, M. Sipahioglu, E. E. Tarim, O. Oymak, and C. Utas, "Bilateral elongated styloid process in an end-stage renal disease patient with peritoneal dialysis: is there any role for ectopic calcification?" European Journal of Dentistry, vol. 3, pp. 155-157, 2009.

[6] K. C. Prasad, M. P. Kamath, K. J. M. Reddy, K. Raju, and S. Agarwal, "Elongated styloid process (Eagle's syndrome): a clinical study," Journal of Oral and Maxillofacial Surgery, vol. 60, no. 2, pp. 171-175, 2002.

[7] M. Ilgüy, D. Ilgüy, N. Güler, and G. Bayirli, "Incidence of the type and calcification patterns in patients with elongated styloid process," Journal of International Medical Research, vol. 33, no. 1, pp. 96-102, 2005.

[8] P. Kursoglu, F. Unalan, and T. Erdem, "Radiological evaluation of the styloid process in young adults resident in Turkey's Yeditepe University faculty of dentistry," Oral Surgery, Oral Medicine, Oral Pathology, Oral Radiology and Endodontology, vol. 100, no. 4, pp. 491-494, 2005. 
[9] W. W. Eagle, "Elongated styloid process: report of two cases," Archives of Otolaryngology, vol. 25, pp. 584-586, 1937.

[10] W. W. Eagle, "Elongated styloid process: symptoms and treatment," Archives of Otolaryngology, vol. 64, pp. 172-176, 1958.

[11] A. J. Camarda, C. Deschamps, and D. Forest, "I. Stylohyoid chain ossification: a discussion of etiology," Oral Surgery, Oral Medicine, Oral Pathology, vol. 67, no. 5, pp. 508-514, 1989.

[12] W. W. Eagle, "The symptoms, diagnosis and treatment of the elongated styloid process," The American Surgeon, vol. 28, pp. $1-5,1962$.

[13] M. H. Lavine, J. C. Stoopack, and T. L. Jerrold, "Calcification of the stylohyoid ligament," Oral Surgery, Oral Medicine, Oral Pathology, vol. 25, no. 1, pp. 55-58, 1968.

[14] S. Patil, S. Ghosh, and N. Vasudeva, "Morphometric study of the styloid process of temporal bone," Journal Clinical Diagnostic Research, vol. 8, no. 9, pp. 4-6, 2014.

[15] P. A. Monsour and W. G. Young, "Variability of the styloid process and stylohyoid ligament in panoramic radiographs," Oral Surgery, Oral Medicine, Oral Pathology, vol. 61, no. 5, pp. 522-526, 1986.

[16] B. R. Chrcanovic, A. L. N. Custódio, and D. R. F. Oliveira, "An intraoral surgical approach to the styloid process in Eagle's syndrome," Oral and Maxillofacial Surgery, vol. 13, no. 3, pp. 145-151, 2009.

[17] L. Balbuena, D. Hayes, S. G. Ramirez, and R. Johnson, "Eagle's syndrome (elongated styloid process)," Southern Medical Journal, vol. 90, no. 3, pp. 331-334, 1997.

[18] T. Jung, H. Tschernitschek, H. Hippen, B. Schneider, and L. Borchers, "Elongated styloid process: when is it really elongated?” Dentomaxillofacial Radiology, vol. 33, no. 2, pp. 119-124, 2004.

[19] R. Vadgaonkar, B. V. Murlimanju, L. V. Prabhu et al., "Morphological study of styloid process of the temporal bone and its clinical implications," Anatomy and Cell Biology, vol. 48, no. 3, pp. 195-200, 2015.

[20] H. A. Balcioglu, C. Kilic, M. Akyol, H. Ozan, and G. Kokten, "Length of the styloid process and anatomical implications for Eagle’s syndrome," Folia Morphologica, vol. 68, no. 4, pp. 265270, 2009.

[21] S. M. Kaufman, R. P. Elzay, and E. F. Irish, "Styloid process variation. Radiologic and clinical study," Archives of Otolaryngology, vol. 91, no. 5, pp. 460-463, 1970.

[22] P. Lindeman, "The elongated styloid process as a cause of throat discomfort. Four case reports," Journal of Laryngology and Otology, vol. 99, no. 5, pp. 505-508, 1985.

[23] R. P. Langlais, D. A. Miles, and M. L. Van Dis, "Elongated and mineralized stylohyoid ligament complex: a proposed classification and report of a case of Eagle's syndrome," Oral Surgery, Oral Medicine, Oral Pathology, vol. 61, no. 5, pp. 527$532,1986$.

[24] S. Winkler, F. J. Sammartino Sr., F. J. Sammartino Jr., and J. H. Monari, "Stylohyoid syndrome. Report of a case," Oral Surgery, Oral Medicine, Oral Pathology, vol. 51, no. 2, pp. 215-217, 1981.

[25] T. Kawai, K. Shimozato, and S. Ochiai, "Elongated styloid process as a cause of difficult intubation," Journal of Oral and Maxillofacial Surgery, vol. 48, no. 11, pp. 1225-1228, 1990.

[26] A. Rathva, D. M. Kubavat, and S. K. Nagar, "Study of styloid process: anatomical variations in length, angulation and distance between the two styloid processes," International Journal Recent Trends Science Technology, vol. 8, pp. 109-112, 2013.
[27] G. Fini, G. Gasparini, F. Filippini, R. Becelli, and D. Marcotullio, "The long styloid process syndrome or Eagle's syndrome," Journal of Cranio-Maxillofacial Surgery, vol. 28, no. 2, pp. 123$127,2000$.

[28] A. Ceylan, A. Köybaşioglu, F. Çelenk, O. Yilmaz, and S. Uslu, "Surgical treatment of elongated styloid process: experience of 61 cases," Skull Base, vol. 18, no. 5, pp. 289-295, 2008. 

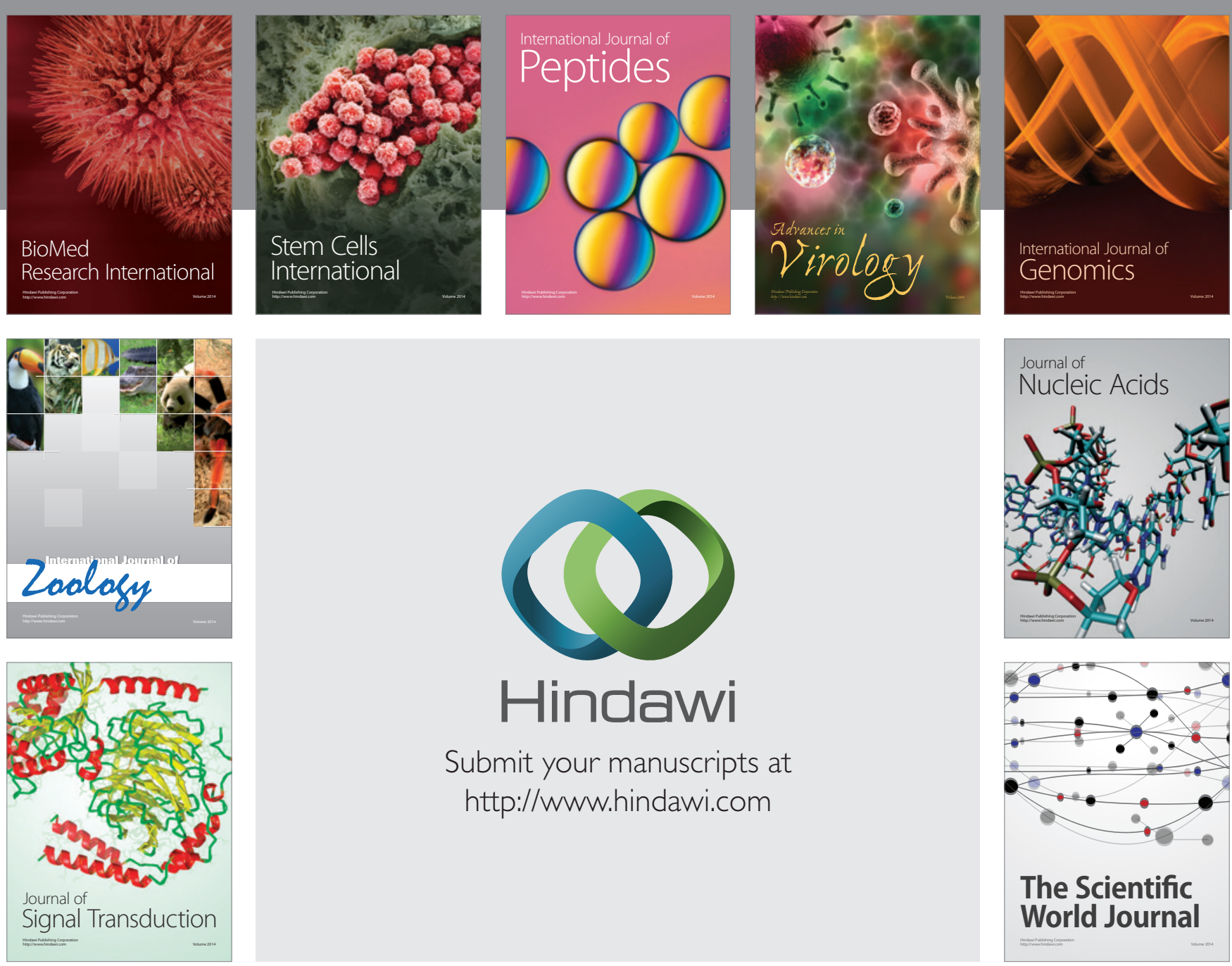

Submit your manuscripts at

http://www.hindawi.com
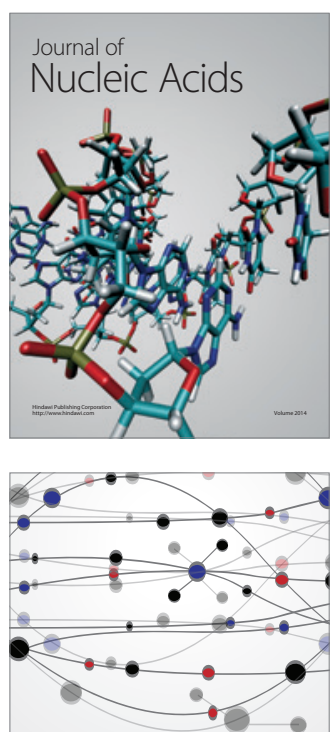

The Scientific World Journal
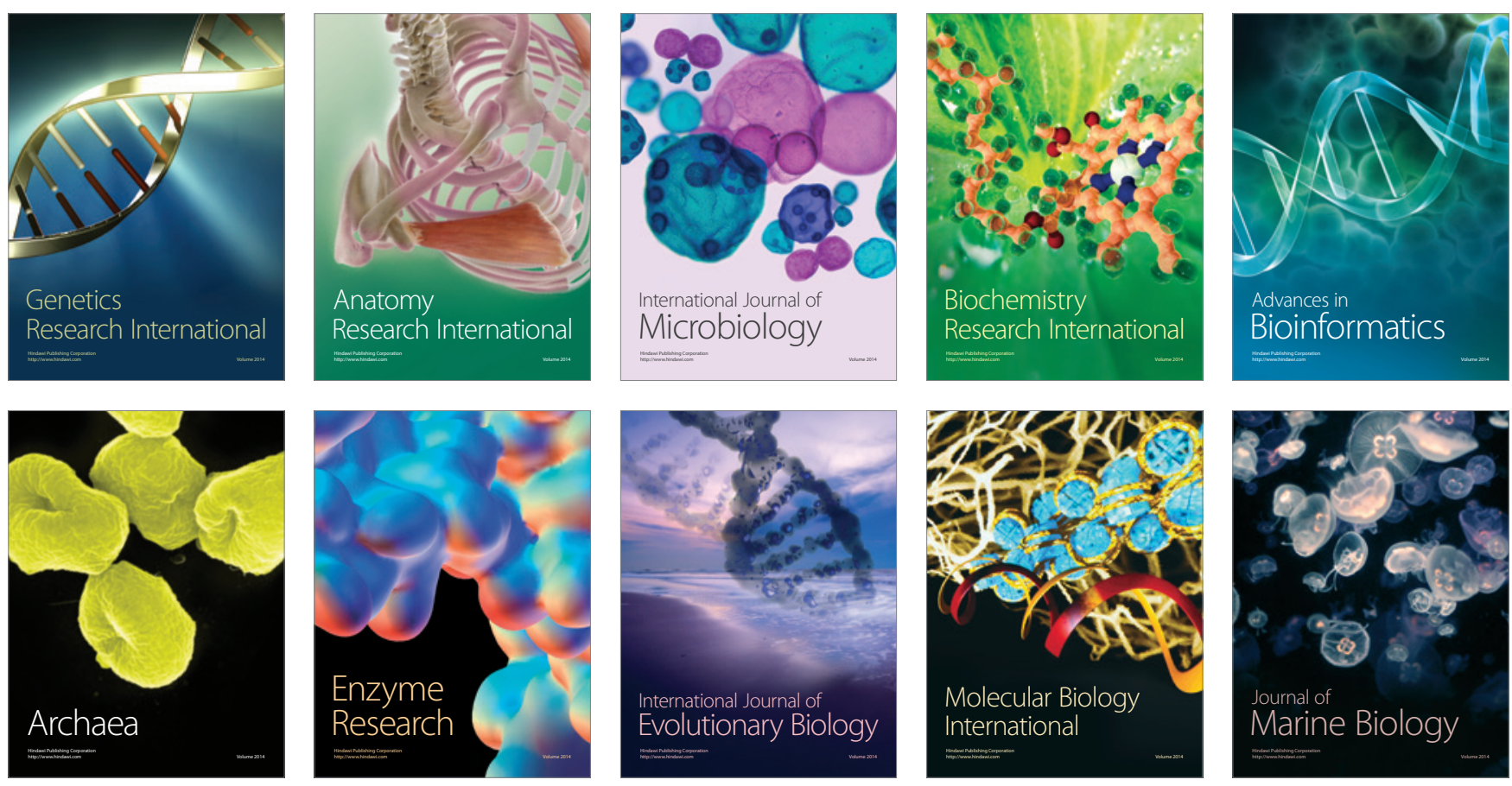